\title{
The Interrelationship between the Release of Renin and Vasopressin as Defined by Orthostasis and Propranolol
}

\author{
Roy Davies, Mary L. Forsling, and J. D. H. Slater, The Cobbold Laboratories \\ and the Department of Physiology, The Middlesex Hospital Medical School, \\ London, W. 1, England
}

\begin{abstract}
A B S T RACT The concentration of both plasma renin and plasma arginine vasopressin rose in normal subjects after an $85^{\circ}$ head-up tilt. Plasma renin activity, which increased $70-80 \%$ above the supine value, was maximal at 15 or $30 \mathrm{~min}$, whereas the six- to sevenfold increase of plasma arginine vasopressin concentration was observed between 30 and $45 \mathrm{~min}$. Intravenous propranolol administered just before tilt was used to investigate the possibility that the delayed rise of arginine vasopressin was stimulated by renin. Although the response of plasma renin was completely abolished by propranolol, the response of vasopressin was unaffected. These findings suggest that the release of vasopressin that follows isosmolar hypovolemia achieved by orthostasis may occur independently of changes in the renin-angiotensin system in the presence of propranolol.
\end{abstract}

\section{INTRODUCTION}

Arginine vasopressin and the renin-angiotensin-aldosterone system together act to maintain osmolar and volume homeostasis in man. Changes in osmolarity appear to be dominant in the control of arginine vasopressin (AVP) ${ }^{1}$ release (1) whereas renin release is mainly modulated by pressure-sensitive mechanisms (2); yet the relationship between these hormones is poorly understood. Because angiotensin infusions have

Received for publication 23 May 1977 and in revised form 2 August 1977.

${ }^{1}$ Abbreviations used in this paper: AVP, arginine vasopressin; PRA, plasma renin activity. been shown to have an antidiuretic action $(3,4)$ and because minute quantities of angiotensin injected into the hypothalamus cause thirst in animals (5), it has been suggested that angiotensin promotes vasopressin release. This possibility has been supported by the demonstration that infusions of angiotensin II lead to vasopressin release in animals $(6,7)$. Conversely, other studies from this laboratory and elsewhere have suggested that vasopressin may inhibit renin release $(8-11)$.

We have recently shown that isosmolar hypovolemia achieved by an $85^{\circ}$ head-up tilt provokes the release of both renin and vasopressin in normal subjects (10), and we have also shown that renin release provoked in this way can be abolished by intravenous propranolol administered just before tilt (12). It is to the question of the possible role of renin in promoting vasopressin release that this present study is addressed, for if indeed the release of vasopressin which follows orthostasis is stimulated by renin, then propranolol should abolish the response of both of these hormones.

\section{METHODS}

The subjects were four healthy medical students aged 20-25 yr. They gave their informed consent. They were receiving no medication and they abstained from food and caffeine- or alcohol-containing drinks for $12 \mathrm{~h}$. The studies commenced at 8:30 a.m. when they lay supine on the tilt bed. At the beginning of this rest period a slow infusion of $0.15 \mathrm{M}$ saline was set up with a left ante-cubital-fossa vein. The tilt began at 10:00 a.m. A control sample was taken 5 min before tilt for estimation of plasma renin activity (PRA), plasma AVP, and plasma osmolarity and further samples were taken at 15,30 , and $45 \mathrm{~min}$. In the period immediately 
TABLE I

The Response of Plasma AVP and PRA to an $85^{\circ}$ Head-up Tilt without and with Intravenous Propranolol

\begin{tabular}{|c|c|c|c|c|c|c|c|c|c|c|c|c|c|c|c|c|c|c|}
\hline \multirow[b]{4}{*}{ Subject } & \multirow[b]{4}{*}{ Sex } & \multirow[b]{4}{*}{ Age } & \multicolumn{16}{|c|}{ Minutes relative to tilt } \\
\hline & & & \multicolumn{2}{|c|}{-5} & \multicolumn{2}{|c|}{+15} & \multicolumn{2}{|c|}{+30} & \multicolumn{2}{|c|}{+45} & \multicolumn{2}{|c|}{-5} & \multicolumn{2}{|c|}{+15} & \multicolumn{2}{|c|}{+30} & \multicolumn{2}{|c|}{+45} \\
\hline & & & \multicolumn{8}{|c|}{ PRA } & \multicolumn{8}{|c|}{ Plasma AVP } \\
\hline & & & C & $\mathbf{P}$ & C & $\mathbf{P}$ & C & $\mathbf{P}$ & C & $\mathbf{P}$ & $\mathrm{C}$ & $\mathrm{P}$ & C & $\mathbf{P}$ & C & $\mathbf{P}$ & $\mathrm{C}$ & P \\
\hline & & $y r$ & \multicolumn{8}{|c|}{$\mathrm{pmol} / \mathrm{h} / \mathrm{ml}$} & \multicolumn{8}{|c|}{$\mu U / m l$} \\
\hline 1 & Male & 23 & 2.0 & 2.2 & 3.2 & 1.5 & 3.4 & 1.8 & 3.0 & 2.1 & 0.5 & 0.6 & 1.3 & 1.5 & 0.3 & 0.3 & 6.0 & 3.3 \\
\hline 2 & Male & 21 & 1.1 & 1.4 & 2.1 & 0.9 & 2.5 & 1.3 & 2.4 & 1.5 & 1.6 & 0.7 & 2.4 & 0.7 & 0.8 & 1.5 & 4.1 & 10.0 \\
\hline 3 & Male & 25 & 2.2 & 2.1 & 3.9 & 0.8 & 3.8 & 1.7 & 3.0 & 2.0 & 0.3 & 2.2 & 0.7 & 1.9 & 1.9 & 1.8 & 4.6 & 3.4 \\
\hline 4 & Female & 24 & 1.9 & 2.0 & 3.3 & 1.3 & 3.4 & 1.5 & 3.1 & 1.8 & 0.4 & 0.3 & 0.7 & 1.3 & 0.5 & 3.0 & 4.5 & 4.7 \\
\hline \multicolumn{2}{|c|}{ Mean } & & 1.8 & 1.9 & 3.1 & 1.1 & 3.3 & 1.6 & 2.9 & 1.9 & $0.7^{*}$ & $0.9 \ddagger$ & 1.3 & 1.4 & 0.9 & 1.6 & $4.8^{*}$ & $5.4 \ddagger$ \\
\hline \multicolumn{2}{|c|}{$\mathrm{SE}$} & & 0.2 & 0.2 & 0.4 & 0.2 & 0.3 & 0.1 & 0.2 & 0.1 & 0.3 & 0.4 & 0.4 & 0.3 & 0.4 & 0.6 & 0.4 & 1.6 \\
\hline
\end{tabular}

In the control study PRA rises by 15-30 min, whereas AVP rises between 30-45 min. The response of PRA is abolished by propranolol, whereas that of plasma AVP is unaffected. C, control tilt; $\mathrm{P}$, propranolol tilt.

$* P<0.001$.

$\ddagger P<0.05$.

preceding tilt, $10 \mathrm{ml}$ of saline or of saline containing propranolol $(0.12 \mathrm{mg} / \mathrm{kg})$ was infused by hand at a steady rate over $2 \mathrm{~min}$, the subjects being unaware of the contents of the syringe. After 1-2 min had elapsed for equilibrium they were tilted to the $85^{\circ}$ head-up position at a constant rate on an electrically operated tilt bed. Heart rate and sphygmomanometric arterial pressure were determined at 5-min intervals throughout each study.

PRA was measured by the radioimmunoassay of angiotensin I generated in a $3-\mathrm{h}$ incubation at $\mathrm{pH} 5.5$ in the presence of inhibitors (13) and plasma AVP was determined by a bioassay in alcohol-anesthetised water-loaded rats as previously described $(14,15)$. Plasma osmolarity was determined by freezing point depression. Data in the text are expressed as mean $\pm \mathrm{SE}$ and, when appropriate, significance is tested by the paired $t$ test.

Validation of the use of PRA to index changes in angiotensin II concentration. The use of PRA to index changes in the renin-angiotensin system has been validated by studies of the effect of propranolol on the response of angiotensin II to tilt. Thus, when five normal subjects were tilted to $85^{\circ}$ for $30 \mathrm{~min}$, after tilt alone, angiotensin II concentration, measured by the method of Düsterdiek and McElwee (16), rose significantly from $11 \pm 2 \mathrm{pg} / \mathrm{ml}$ to $27 \pm 5 \mathrm{pg} / \mathrm{ml}$ by $15 \mathrm{~min}$ and to $29 \pm 8 \mathrm{pg} / \mathrm{ml}$ by $30 \mathrm{~min}(P<0.05$ for both). In contrast, when these studies were repeated with intravenous propranolol, the values for angiotensin II of $13 \pm 4$ $\mathrm{pg} / \mathrm{ml}$ and $16 \pm 3 \mathrm{pg} / \mathrm{ml}$, which were observed at 15 and 30 min, respectively, did not differ significantly from the supine value of $14 \pm 4 \mathrm{pg} / \mathrm{ml}$. PRA, which was also measured in that study, closely paralleled the changes in angiotensin II.

\section{RESULTS}

Control tilt studies. PRA rose significantly in all subjects so that all values after tilt were greater than the corresponding supine values. The maximum value of $3.30 \pm 0.3 \mathrm{pmol} / \mathrm{h}$ per $\mathrm{ml}^{2}$ was seen at $30 \mathrm{~min}$, an

\footnotetext{
${ }^{2} 1 \mathrm{pmol} / \mathrm{h}$ per $\mathrm{ml}=1.297 \mathrm{ng} / \mathrm{h}$ per $\mathrm{ml}$.
}

increase of some $80 \%$ above the mean supine value. Plasma vasopressin concentration also rose in all subjects. However, the time course of the change of vasopressin differed from that of plasma renin. Thus, the supine, 15-, and 30-min values of plasma AVP of $0.7 \pm 0.3,1.3 \pm 0.4$, and $0.9 \pm 0.4 \mu \mathrm{U} / \mathrm{ml}$, respectively, did not differ significantly one from the other, whereas between 30 and $45 \mathrm{~min}$ it rose to $4.8 \pm 0.4 \mu \mathrm{U} / \mathrm{ml}(45$ min vs. supine, $t=6.65, P<0.001)$. This is a mean increase of some $700 \%$ above the mean supine value (Table I).

Tilt studies with propranolol. The supine value for PRA of $1.9 \pm 0.2 \mathrm{pmol} / \mathrm{h}$ per ml was similar to that observed in the control study. After propranolol the response of PRA to tilt was completely abolished so that the 15-, 30-, and 45-min values were all highly significantly less than the corresponding values in the control tilt ( $t$ varies from 4.96 to $13.1, P$ varies from $<0.01$ to $<0.001)$. In sharp contrast to PRA, the response of plasma AVP was no different from that observed in the control study. Thus the supine, 15-, and 30 -min values of $0.9 \pm 0.4,1.4 \pm 0.3$, and $1.6 \pm 0.6$ $\mu \mathrm{U} / \mathrm{ml}$, respectively, did not differ significantly one from the other, but, as in the control study, plasma AVP rose strikingly between 30 and $45 \mathrm{~min}$ to a mean value of $5.4 \pm 0.9 \mu \mathrm{U} / \mathrm{ml}$. This is a mean increase of some $600 \%$ above the mean supine value $(45 \mathrm{~min}$ vs. supine, $t=2.48, P<0.05$ ) (Table I).

Plasma osmolarity, which was estimated in both studies, did not vary by more than $2.0 \mathrm{mosmol} / \mathrm{liter}$ in any of the subjects and such variation as did occur was nonsystematic relative to the response of AVP.

The mean supine heart rate rose from $68 \pm 4$ beats/ $\min$ to $82 \pm 5$ beats $/ \mathrm{min}$ by $5 \mathrm{~min}$ in the control study and varied little thereafter. After propranolol 
the supine heart rate fell slightly from $69 \pm 3$ to $66 \pm 1$ beats/min, rising to $73 \pm 2$ beats/min by 5 min of tilt. Arterial pressure was $118 \pm 5 / 74 \pm 3$ supine and settled to a mean value of $115 \pm 6 / 82 \pm 4$ within 5 min of tilt. It did not vary significantly thereafter. Intravenous propranolol had no effect upon either the supine arterial pressure or upon the response of arterial pressure to tilt.

\section{DISCUSSION}

This study confirms our earlier report of a rise of both PRA and plasma AVP in response to an $85^{\circ}$ tilt (10). The peak value for PRA, which we have shown closely to reflect changes in angiotensin II, was seen at 15-30 min, while the major rise of plasma AVP occurred between 30 and $45 \mathrm{~min}$. One possible interpretation of the relative timing of these responses is that the early rise of PRA, acting via angiotensin, provokes AVP release. Indeed there is some evidence to support this possibility for angiotensin has potent antidiuretic and thirst-stimulating actions (3-5) and a number of studies in animals have supported the idea that angiotensin acts by promoting vasopressin release. Thus, Anderson and Erikson (17) reported that small quantities of angiotensin infused into the third ventricle of the goat cause an antidiuresis. Subsequently Bonjour and Malvin (6) reported that intravenous infusions of angiotensin or of renin in conscious dogs results in a rise in plasma AVP concentration and, because in a further study they found that intracarotid infusions of angiotensin had a greater effect, they postulated that angiotensin acts centrally to promote AVP release (7). These studies have been criticized because they employed pharmacological doses of angiotensin, but recently Blaine and Zimmerman (18) have reported that intracarotid infusions of angiotensin to give plasma concentrations within the physiological range reduce free water clearance in conscious sheep.

A contrary view has been taken by Claybaugh et al. (19), who found that angiotensin infusions in dogs have no effect on AVP release. Similarly, Share et al. (20) were unable to demonstrate a rise of plasma AVP concentration in normal subjects despite a rise of PRA, and they have claimed that renin has no effect on vasopressin release in man. Although it is difficult to be certain of the reasons for the discrepancy between our data and those of Share et al., the likeliest explanation is in the nature of the postural stimulus employed, for, whereas we have used an $85^{\circ}$ tilt, Share et al. sampled for AVP after $4 \mathrm{~h}$ of quiet ambulation.

In this present study we have observed unequivocal increases in both PRA and plasma AVP concentration after tilt. The reason for the delay in the AVP response that we have observed in this and in our pre- vious study (10) remains obscure: in dogs systolic hypotension has been shown to provoke AVP release by baroreceptor activation (21) but we have found no evidence of arterial pressure change in either the control or propranolol tilt studies. Another possible explanation is that the fall in plasma volume which proceeds rapidly during the first $30 \mathrm{~min}$ after tilt $(10,22)$ reaches a critical level, provoking AVP release. This present study has explored the other possible explanation that AVP release is provoked by the reninangiotensin system. However, while the response of PRA (and of angiotensin II) can be completely abolished by propranolol, that of AVP is unaffected, and we therefore conclude that the release of AVP which follows orthostasis in man may occur independently of changes in the renin-angiotensin system in the presence of propranolol.

\section{ACKNOWLEDGMENTS}

We thank Mrs. N. Payne and Mr. H. Williams for skillful technical assistance, Dr. A. Melionis, who performed the angiotensin II determinations, and the Special Trustees of the Middlesex Hospital for the provision of essential facilities.

\section{REFERENCES}

1. Verney, E. B. 1947. The antidiuretic hormone and the factors which control its release. Proc. R. Soc. Lond. B. Biol. Sci. 135: 25-106.

2. Laragh, J. H., and J. E. Sealey. 1973. Renin-angiotensinaldosterone system. Handb. Physiol. (Sect. 8. Renal Physiology) 831-908.

3. Genest, J. 1961. Angiotensin, aldosterone, and human arterial hypertension. Can. Med. Assoc. J. 84: 403-419.

4. Brown, J. J., and W. S. Peart. 1962. The effect of angiotensin on urine flow and electrolyte excretion in hypertensive patients. Clin. Sci. (Oxf.). 22: 1-17.

5. Fitzsimmons, J. T. 1970. The renin angiotensin system in the control of drinking. In The Hypothalamus. L. Martini, M. Motta, and F. Fraschini, editors. Academic Press, Inc., New York. 195-212.

6. Bonjour, J-P., and R. L. Malvin. 1970. Stimulation of ADH release by the renin-angiotensin system. Am. J. Physiol. 218: 791-799.

7. Mouw, D., J-P. Bonjour, R. L. Malvin, and A. Vander. 1971. Central action of angiotensin in stimulating ADH release. Am. J. Physiol. 220: 239-242.

8. Bunag, R. D., I. H. Page, and J. W. McCubbin. 1967. Inhibition of renin release by vasopressin and angiotensin. Cardiovasc. Res. 1: 67-72.

9. Khokhar, A. M., J. D. H. Slater, M. L. Forsling, and N. N. Payne. 1976. Effect of vasopressin on plasma volume and renin release in man. Clin. Sci. Mol. Med. 50: 415-424.

10. Davies, R., J. D. H. Slater, M. L. Forsling, and N. N. Payne. 1976. The response of arginine vasopressin and plasma renin to postural change in normal man, with observations on syncope. Clin. Sci. Mol. Med. 51: 267274.

11. Hesse, B., and I. Nielson. 1977. Suppression of plasma renin activity by intravenous infusion of anti-diuretic hormone in man. Clin. Sci. Mol. Med. 52: 357-360.

12. Davies, R., and J. D. H. Slater. 1976. Is the adrenergic 
control of renin release dominant in man? Lancet. II: $594-596$.

13. Menard, J., and K. J. Catt. 1972. Measurements of renin activity by radioimmunoassay of angiotensin I. Endocrinology. 90: 422-430.

14. Forsling, M. L., J. J. Jones, and J. Lee. 1968. Factors influencing the sensitivity of the rat to vasopressin. $J$. Physiol. (Lond.). 196: 495-505.

15. Forsling, M. L. 1974. Extraction of neurohypophyseal hormones for bioassay. J. Physiol. (Lond.). 241: 3P.

16. Düsterdiek, G., and G. McElwee. 1971. Estimation of angiotensin II in human plasma by radioimmunoassay. Some applications to physiological and clinical states. Eur. J. Clin. Invest. 2: 32-38.

17. Anderson, B., and L. Erikson. 1971. Conjoint action of sodium and angiotensin on brain mechanisms controlling water and salt balance. Acta Physiol. Scand. 81: $18-29$.
18. Blaine, E. H., and M. B. Zimmerman. 1976. Free water clearance after intracarotid angiotensin II in conscious sheep. Endocrinology. 98(Suppl.): 333.

19. Claybaugh, J. R., L. Share, and K. Shimuzi. 1972. The inability of infusions of angiotensin to elevate the plasma vasopressin concentration in the anaesthetised dog. Endocrinology. 90: 1647-1652.

20. Share, L., J. R. Claybaugh, F. E. Hatch, J. G. Johnson, S. Lee, E. E. Muirhead, and P. Shaw. 1972. Effect of posture and sodium depletion on plasma levels of vasopressin and renin in normal subjects. J. Clin. Endocrinol. Metab. 35: 171-174.

21. Share, L., and M. N. Levy. 1966. Carotid sinus pulse pressure, a determinant of plasma antidiuretic hormone concentration. Am. J. Physiol. 211: 721-724.

22. Nielsen, I., and I. Møller. 1968. The relationship between plasma renin activity and haemoconcentration. Acta Med. Scand. 183: 381-386. 